Check for updates

Cite this: RSC Adv., 2017, 7, 27707

Received 24th February 2017

Accepted 18th May 2017

DOI: $10.1039 / \mathrm{c} 7 \mathrm{ra02335a}$

rsc.li/rsc-advances

\section{Energy and chemical conversion of five Australian lignocellulosic feedstocks into bio-crude through liquefaction $\uparrow$}

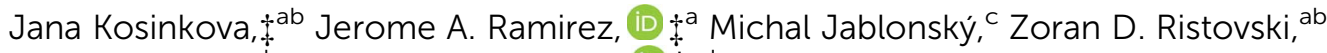 \\ Richard Brown ${ }^{\text {ad }}$ and Thomas J. Rainey (D) *ad
}

Thermal liquefaction of five potential feedstocks namely, banana bunch stems (BBS), pineapple tops (PT), Forage sorghum (FS), bagasse (Ba) and Arundo donax (AD) were examined from an energy perspective at a large laboratory scale. Comparison of oil yield and higher heating value (HHV) of feedstock and biocrude at this scale enabled analysis of the energy efficiency of the liquefaction of feedstock with varying structural compositions under different reaction conditions. Arundo donax was used to investigate degradation behaviour for bio-crude production at temperatures between $250-350{ }^{\circ} \mathrm{C}$ and biomass/ solvent ratios of $1 / 10$ to $1 / 25$ (wt/wt). Maximum bio-crude yield of $67.3 \%$ was observed for $A D$ at $350{ }^{\circ} \mathrm{C}$ and biomass/solvent ratio of $1 / 15$. Liquefaction with recycled solvent in the first run improved energy recovery and the heating value of the bio-crude in comparison with fresh solvent. On the basis of the energy conversion, the feedstocks ranked as follows: BBS $(105 \%)>$ FS $(77 \%)>\mathrm{Ba}(57 \%)>\mathrm{PT}(55 \%)>\mathrm{AD}$ (40\%). GCMS results showed that the chemical composition changed in distribution and relative abundance of the oxygenated compounds, varying significantly depending on the type of biomass. Analysis of energy input and output of varying conditions and feedstock showed energy requirements and the HHV varied with the feedstock.

\section{Introduction}

Energy supply has become a problem that has lately drawn public attention.

Reports and studies have estimated the peak production of fossil oil between 2017-2035. ${ }^{1}$ Aside from the wide variations in the estimate of the date of peak oil, the balance of supply and pricing can be disturbed by multiple uncertain factors such as politico-economical quarrels, environmental challenges, and geopolitical disputes.

Moreover, heavy reliance on fossil fuels has brought a diversity of environmental and health problems. These reasons have necessitated the need to investigate new, renewable, and

\footnotetext{
${ }^{a}$ School of Chemistry, Physics and Mechanical Engineering, Science and Engineering Faculty, Queensland University of Technology, O Block Level 7 708, 2 George St, Brisbane, Queensland 4000, Australia. E-mail: t.rainey@qut.edu.au; Tel: +61 73138 1977

${ }^{b}$ International Laboratory for Air Quality and Health, Queensland University of Technology, Australia

'Department of Wood, Pulp and Paper, Slovak University of Technology in Bratislava, Radlinského 9, 81237 Bratislava, Slovakia

${ }^{d}$ Biofuel Engine Research Facility, Queensland University of Technology, O Block Level 7 708, 2 George St, Brisbane, QLD 4000, Australia

$\dagger$ Electronic supplementary information (ESI) available. See DOI: 10.1039/c7ra02335a

$\ddagger$ These authors contributed equally to this work.
}

sustainable resources of energy that are secure for the long term.

Biofuels have received significant attention as an alternative to fossil fuels from many research groups over the world. ${ }^{2-4}$ The main approach is to develop clean technology for production of second-generation biofuels by recycling waste and biomass residues. Many previous surveys showed the abundance of waste fibre from numerous industries and their potential to be sustainably converted into high-value products such as liquid fuels. $^{3-5}$ This potential is well-positioned to meet the IEA (International Energy Agency) "Blue map scenario" projection that $26 \%$ of biofuels in the transport sector in 2050 are expected to be from second generation feedstock. ${ }^{5}$

Thermochemical processes have been identified as an important technology for biofuel production. Liquefaction is one of the preferred processes from this group-it uses high pressure and temperature to directly convert biomass with potentially high water content without expensive dewatering processes. ${ }^{6}$ This process has viability to become one of the routes for converting multiple feedstocks into valuable biobased products at a commercial scale. The focus in the literature relates to changing various process parameters for liquefaction (e.g. temperature and headspace gas) to improve the properties of biofuels to meet biofuel standards. ${ }^{7-11}$ Although water is a relatively cheap and abundant solvent, the use of other solvents in liquefaction has also been explored to observe 
effects of these solvents' different physical and chemical properties on the liquefaction process and the properties of the biocrude oil. ${ }^{8-10}$ Moreover, the high temperature and pressure required to perform liquefaction in the supercritical regime may be reduced by using organic solvents. ${ }^{12}$

One of the most influential parameters for the large-scale conversion process is ensuring a constant supply of biomass, which depends on the type. In recent years, fast-growing energy crops such as Arundo donax (A. donax) and Forage sorghum have been promoted as new sources of feedstock for biofuel production. A. donax is a tall perennial grass also known as Giant Reed that can grow spontaneously in harsh environments such as in the vicinity of Australian salt pans and in saline waters. ${ }^{13}$ This non-food crop is produced in remarkably high yields; for example, $51 \mathrm{t} \mathrm{ha}^{-1}$ of dry matter was obtained in 43 weeks on arable land irrigated with sewerage. ${ }^{14}$ Another energy crop, sorghum, is presently widespread across Australia; genetic diversity allows adaption and rigorous growth in different climates. ${ }^{15}$ Forage sorghum's average harvesting yield is $14.2 \mathrm{t}$ $\mathrm{ha}^{-1}$ in a five-month harvesting window. ${ }^{16}$ Nowadays, it is receiving global interest as a multi-product crop for animal feeding and bioethanol fermentation. Agricultural residues are another class of energy feedstocks that might ensure year-round accessibility in the supply chain. One of the larger fruit industries in Australia is the banana industry which produced 372000 tonnes in 2013-2014. ${ }^{17}$ Currently, waste banana palms are used in the production of veneer and panel products. Every one tonne of banana production generates about 4 tonnes of lignocellulosic waste, predominantly pseudostems. ${ }^{18}$ Another large Australian fruit industry is pineapple, which produced around 85000 tonnes of fresh and processed fruit in 2009-10. ${ }^{19}$ Pineapple waste normally consists of the parts that are not suitable for consumption such us leaves, pulp, stem and peels. Stem and leaf waste accounts for $50 \%$ of total pineapple weight and occasionally used in paper production, and as a fertilizer or animal feed ${ }^{20}$ Another large agricultural industry in Australia, sugarcane production is at over 30 million tonnes per year, generating 3 tonnes of leftover fibre (bagasse) for every 10 tonnes of sugarcane crushed. ${ }^{21}$ The energy value of bagasse is demonstrated by sugar mills directly burning bagasse on site to produce steam and electricity. ${ }^{22}$

Use of the aforementioned biomass has already been investigated through thermochemical conversion processes in the literature. ${ }^{23-27}$ However, little research is conducted on the evaluation of liquefaction processing by assessing energy conversion efficiency. Liquefaction is in competition with pyrolysis conversion process in terms of energy efficiency and so more detailed information about energy conversion is required. More accurate data can be generated using larger scale testing, as performed in this study. The larger scale also permits the generation of larger samples and direct measurement of Higher Heating Value (HHV).

With a view of large-scale alternative biofuel production, it is necessary to determine the change of the energy content from biomass to bio-crude, as well as determining the energy required in producing the bio-crude. Many previous liquefaction studies have focussed on bio-crude yield and only a few focused on the overall conversion of energy from feedstock to bio-crude. The overall energy conversion incorporating significant variability in the HHV of the initial feedstock, the HHV of the bio-crude as well as the conversion yield is of important interest when analysing liquefaction of various feedstock that are readily available. This gives insight to the viability of liquefying local agricultural wastes or energy crops as an indigenous energy source. Moreover, the effect of changing the temperature, the biomass/solvent ratio and solvent recycling on energy efficiency was also observed. In these experiments, $A$. donax was used with varying reaction temperature, biomass/ solvent ratio and solvent recycling, which are all important considerations in large scale production. The relationship between HHV and different structural composition of the potential feedstocks was also observed. The effect of heterogeneity of the main lignocellulosic constituents on diversity and abundance of bio-crude oils' chemical composition was determined.

\section{Material and methods}

\subsection{Biomass feedstocks}

Five kinds of lignocellulosic biomass were obtained from local industries in Queensland, Australia, as well as the Queensland Department of Agriculture and Fisheries including: Arundo donax (AD), bagasse (Ba), banana bunch stem (BBS), pineapple tops (PT), and Forage sorghum (FS). The feedstocks were cut to a similar size $(\sim 10 \mathrm{~mm})$. Table 1 is provided to give the reader an overview of each material including structural and ultimate analysis (see Section 2.3 for methods). The chemical composition of the biomass determines the quantity and quality of the produced bio-crude oils. All studied biomasses had more or less similar holocellulose and lignin content except BBS. The lowest value of lignin and highest content of holocellulose were found in this sample suggesting greater conversion rate than others. Previous studies, moreover, had found high cellulose content in BBS, which increase the bio-crude oil yield..$^{28,29}$ Generally, the extractives comprise low molecular compounds soluble in low polarity solvents. The values of extractives were varied amid the

Table 1 Chemical and elemental composition (wt\% of dry basis)

\begin{tabular}{|c|c|c|c|c|c|}
\hline & $\mathrm{AD}$ & $\mathrm{Ba}$ & BBS & PT & FS \\
\hline Ash (dry wt\%) & 3.3 & 9.3 & 12.4 & 7.1 & 3.2 \\
\hline Moisture (wt\%) & 23.4 & 14.9 & 37.8 & 13.8 & 13.2 \\
\hline \multicolumn{6}{|c|}{ Structural analysis (\%) } \\
\hline Lignin & 20.9 & 20.5 & 7.9 & 20.9 & 23.3 \\
\hline Holocellulose & 75.8 & 70.2 & 79.7 & 72.1 & 73.4 \\
\hline Extractives & 9.17 & 5.04 & 25.16 & 34.86 & 7.77 \\
\hline \multicolumn{6}{|c|}{ Ultimate analysis (\%) } \\
\hline $\mathrm{C}$ & 43.36 & 43.27 & 47.08 & 39.36 & 45.51 \\
\hline $\mathrm{H}$ & 5.79 & 5.51 & 6.39 & 5.16 & 5.84 \\
\hline $\mathrm{N}$ & 0.36 & 0.47 & 2.65 & 2.38 & 0.28 \\
\hline $\mathrm{O}^{a}$ & 50.50 & 50.94 & 43.88 & 53.10 & 48.37 \\
\hline
\end{tabular}

${ }^{a}$ Calculated by difference. 
samples. Similar values were detected in $\mathrm{AD}, \mathrm{Ba}$ and $\mathrm{FS}$ ranging between 5-9\%. Whereas the highest value had BBS and PT with $25.16 \%$ and $34.86 \%$, respectively. The ash content represents the inorganic content in the biomasses. The values fluctuated greatly with the highest content of $12.4 \%$ in BBS. Overall, the biomasses had higher carbon and oxygen content (49-47\% and $43-50 \%$ respectively), and lower hydrogen content of $5-6 \%$. Therefore the HHVs of the samples were relatively low. While nitrogen contents in $\mathrm{AD}$ and $\mathrm{FS}$ were negligible $(0.36 \%$ and $0.28 \%$ respectively), the highest value was found in BBS sample (2.65\%). HHVs of the feedstocks are provided and discussed in the Section 3.3.

\subsection{Thermal liquefaction process and product recovery}

All experiments were performed in a $1.8 \mathrm{l}$ Parr batch reactor (Parr Instruments Co.). Since the research team had great sufficiency of A. donax, it was used for initial ranging experiments in order to guide process conditions for other feedstocks. $20 \mathrm{~g}$ of dried biomass was loaded with acetone as solvent in various biomass/solvent $(\mathrm{B} / \mathrm{S}) \mathrm{wt} / \mathrm{wt}$ ratios $(1: 1,1: 15,1: 20$, and $1: 25)$. The maximum allowable loading limit was calculated based on the type of vessel alloy, maximum solvent ratio (i.e. $25: 1$ ) and the volume multiplier factor. Furthermore, the fibre density of the feedstocks was considered. The acetone as solvent was selected because of industrial interest, economic feasibility and its high-effectiveness. ${ }^{9,30}$ Furthermore, highest conversion rate and lower viscosity were previously reported with acetone as a solvent. ${ }^{9,31,32}$ Nitrogen was used to evacuate air and pressurize the headspace of the reactor to $10 \mathrm{bar}$. The reaction was started by heating the vessel to the desired temperature $\left(250{ }^{\circ} \mathrm{C}, 300{ }^{\circ} \mathrm{C}\right.$ and $\left.350{ }^{\circ} \mathrm{C}\right)$ then holding the temperature for $30 \mathrm{~min}$, with stirring. At the end of the reaction, water passing through an internal pipe cooled down the reactor to room temperature.

All separation processes are shown schematically in Fig. 1. Following liquefaction, the gas was vented and the reaction mixture was drained for separation. Vacuum filtration through a Whatman's no. 5 separated solid residues (SR) from the solvent soluble fraction. SR was further dried overnight in the oven at $105{ }^{\circ} \mathrm{C}$. The bio crude (oil) was recovered by evaporating solvent (acetone and water) out from the mixture under reduced pressure. In some experiments the remaining solvent fraction was recycled into subsequent liquefaction runs.

Standard deviation was calculated and showed negligible difference between oil and SR yields between duplicates (SD < $1 \%)$. The low standard deviation was caused by the high repeatability associated with the reactor which is 1-2 orders of magnitude larger than used in other liquefaction studies.

\subsection{Analysis of products}

Each raw material was analysed by ASTM method E1755 and E1756 to determine the ash and moisture contents respectively. Structural analysis of the feedstocks was measured following NREL/TP-510-42619 (extractives) and TAPPI T222 (Klason lignin). HHV of feedstocks and liquefaction oil was determined using a Parr 6200 Bomb Calorimeter. Elemental analyses of the feedstock and solid residues were conducted using LECO TruSpec Micro CHNS. Furthermore, HHV (MJ kg ${ }^{-1}$ ) of all biomasses were predicted based on carbon content using the following eqn (1) suggested by Jablonsky et al. ${ }^{33}$

$$
\mathrm{HHV}_{\text {model }}=C \times 0.40659
$$

where $C$ is the carbon content (wt\%) of the sample. In order to study the changes of chemical groups between each product and its raw material Fourier transform infrared spectrometer (FTIR) was employed in the spectral range of $4000-400 \mathrm{~cm}^{-1}$.

The chemical composition of the oils was analysed by gas chromatography (Thermo Scientific, Trace 1310) equipped with a single quadrupole mass selective detector (ISQ). Each sample was dissolved and diluted in dichloromethane. The GC injector was set at $250{ }^{\circ} \mathrm{C}$ and a TG5ms column (length $30 \mathrm{~m}$, ID 0.25 $\mathrm{mm}$, film $0.25 \mathrm{~mm}$ ) was used. The GC was running in constant flow mode at $1.4 \mathrm{ml} \mathrm{min}^{-1}$. To get a good product separation the oven was programmed at an initial temperature at $50{ }^{\circ} \mathrm{C}$ (held for 1 minute) then ramped at a constant rate of $10{ }^{\circ} \mathrm{C} \mathrm{min}^{-1}$ to $300{ }^{\circ} \mathrm{C}$ and held for $9 \mathrm{~min}$, with a split ratio of 10 . The MS transfer line and ion source temperatures were both set to $250{ }^{\circ} \mathrm{C}$ and the MS scanned $\mathrm{m} / \mathrm{z}$ range of $40-0 \mathrm{amu}$, with a 1.8 minutes solvent cut and a scan time of $0.05 \mathrm{~s}$.

The conversion yields of the oil product and SR were defined as ratios of masses of the respective fractions to the initial mass of raw material and were expressed in mass percentages in dry basis. The total yield of remnant fractions (RP); gas and solvent solubles (acetone and water), were approximated by difference. To precisely assess the efficiency of the liquefaction process, the oil yield has been factored in to come up with the energy conversion (EC), given by eqn (2). The EC shows the change in the chemical energy content of the feedstock as it converts to oils through liquefaction.

$$
\% \text { energy conversion }(\mathrm{EC})=\frac{\text { oil yield } \times \mathrm{HHV}_{\mathrm{o}}}{\mathrm{HHV}_{\mathrm{f}}} \times 100
$$

where $\mathrm{HHV}_{\mathrm{o}}$ and $\mathrm{HHV}_{\mathrm{f}}$ are high heating values of oil and feedstock, respectively.

It is important to note, however, that the energy conversion values do not include the heat supplied to carry out reactions as

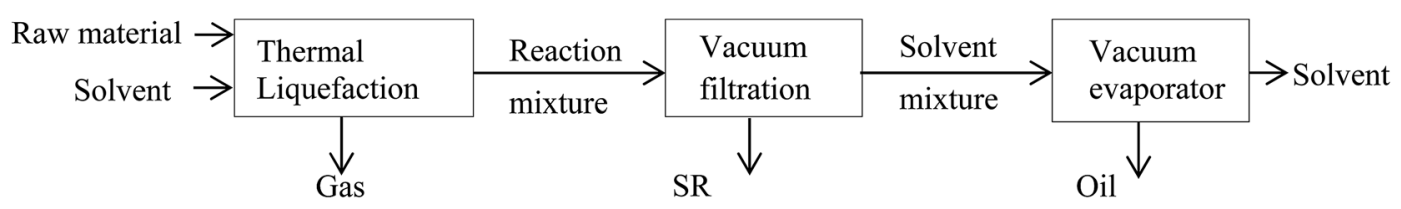

Fig. 1 Separation process of the products. 
energy input and consequently, heat recovery and insulation were out of the scope. The effect of incremental energy input to reach the liquefaction temperature was not considered in eqn (2) in assessing the overall energy change from feedstock to oil. The approximate energy required to heat the solvent-biomass mixture from the initial temperature of $20{ }^{\circ} \mathrm{C}$ to the final temperature of reaction was calculated using eqn (3), similar with the approach taken by Minowa et al. ${ }^{27}$

$$
\text { Energy input }=\mathrm{HHV}_{\mathrm{f}} m_{\mathrm{f}}+\left(m_{\mathrm{f}} C_{\mathrm{f}}+m_{\mathrm{s}} C_{\mathrm{s}}\right)\left(T_{\mathrm{r}}-T_{\mathrm{i}}\right)
$$

where $m_{\mathrm{f}}$ is the mass of biomass feedstock, $C_{\mathrm{f}}$ is the heat capacity of feedstock, $m_{\mathrm{s}}$ is the mass of solvent, $C_{\mathrm{s}}$ is the heat capacity of the solvent, $T_{\mathrm{r}}$ is the reaction temperature and $T_{\mathrm{i}}$ is the initial temperature. Eqn (3) provides the calculation method for the sensible heat required to heat the mixture of solid biomass and solvent (acetone) to the reaction temperature. The heat capacity of the solid biomass is calculated using $C=5.340 T$ - 299 ( $T$ in kelvin, $C$ in $\mathrm{J} \mathrm{kg}^{-1} \mathrm{~K}^{-1}$ ), as suggested by Dupont et $a .^{34}$ In contrast with pyrolysis, the liquefaction process involves heating not only the feedstock but also the solvent, which may represent significant heat requirements; thus determining the incremental heat input between operating temperatures is relevant. This approach recognises that the energy balance has shortcomings in accounting for the enthalpies of reactions involved in liquefaction. This is mainly due to the plethora of reactions postulated to be occurring during liquefaction, ${ }^{23}$ not all have been thoroughly characterised. The kinetics of these reactions is in itself is a burgeoning area of study. Moreover, the discussion on energy inputs, outputs and conversions are confined to only the reaction system where reactants are converted to products. This is in recognition that while the experimental set-up may not adequately represent all liquefaction set-ups where energy is recovered or recycled, the thermochemical changes within the reaction system are comparable to similar systems.

For recycling runs, energy input was calculated with a modified equation considering the new solvent initial temperature after mixing the recycled solvent with fresh solvent. The new solvent initial temperature is calculated using eqn (4), assuming that fresh solvent and recycled solvent are mixed to equilibrium temperature prior to the liquefaction process.

$$
T_{\mathrm{is}}=\frac{T_{\mathrm{r}} m_{\mathrm{hs}}+T_{\mathrm{i}} m_{\mathrm{cs}}}{m_{\mathrm{cs}}+m_{\mathrm{hs}}}
$$

where $T_{\mathrm{is}}$ is the initial temperature of the solvent, $m_{\mathrm{hs}}$ is the mass of the hot solvent from recycle and $m_{\mathrm{cs}}$ is the mass of the cool solvent. A constant heat capacity of the solvent is assumed, and the heat capacities of organics dissolved in recycled solvent is assumed to be negligible for this purpose. The modified equation for energy input is given by eqn (5).

$$
\text { Energy input }=\mathrm{HHV}_{\mathrm{f}} m_{\mathrm{f}}+m_{\mathrm{f}} C_{\mathrm{f}}\left(T_{\mathrm{r}}-T_{\mathrm{i}}\right)+m_{\mathrm{s}} C_{\mathrm{s}}\left(T_{\mathrm{r}}-T_{\mathrm{is}}\right)
$$

The adjusted energy recovery $\left(\mathrm{ER}_{\mathrm{adj}}\right)$ is the ratio of energy output to input calculated using eqn (6).

$$
\text { Energy recovery }\left(\mathrm{ER}_{\mathrm{adj}}\right)=\frac{\mathrm{HHV}_{\mathrm{o}} \mathrm{m}_{\mathrm{o}}}{\text { energy input }} \times 100 \%
$$

where $m_{\mathrm{o}}$ is the mass of the bio-crude.

\section{Result and discussion}

\subsection{Optimization of reaction parameters on products distribution and energy}

There are many liquefaction parameters that strongly influence conversion rate and composition of the oils. In this paper we studied the effect of two important parameters, namely temperature (with $1 / 15 \mathrm{wt} / \mathrm{wt}, \mathrm{B} / \mathrm{S}$ ratio) and $\mathrm{B} / \mathrm{S}$ ratio at $300{ }^{\circ} \mathrm{C}$. The experimental conditions were determined based on optimal values for liquefaction as described in existing literature. ${ }^{7,27}$ All experiments using $\mathrm{AD}$ were operated in nitrogen atmosphere for $30 \mathrm{~min}$ with acetone as a solvent. The results are summarized in Table 2.

In general, an increased liquefaction temperature has a beneficial effect for oil yield. Several tests were directed at operational temperatures $250{ }^{\circ} \mathrm{C}, 300{ }^{\circ} \mathrm{C}$ and $350{ }^{\circ} \mathrm{C}$ (Table 2). The results highlighted that the useful temperature range to produce sufficient amount of oil was $300-350{ }^{\circ} \mathrm{C}$. Aysu and Küçük ${ }^{35}$ studied the effect of various solvents (including acetone) on $A$. donax at three different temperatures $(245,265$ and $285^{\circ} \mathrm{C}$ ) and found a trend between temperature and yield which was comparable with this study.

Energy conversion and HHV of oil from AD were best when liquefied at $350{ }^{\circ} \mathrm{C}$. This is due to the higher energy available to break down polymers in biomass. ${ }^{11}$ Increasing conversion with increasing temperature is a common observation in other liquefaction studies, though in some a maximum conversion temperature was observed. ${ }^{35}$ Further analysis of incremental energy inputs and output revealed that when increasing the reaction temperature from $250{ }^{\circ} \mathrm{C}$ to $350{ }^{\circ} \mathrm{C}$, an additional 2.28 $\mathrm{MJ} \mathrm{kg}^{-1}$ of heat input ( $+8 \%$ ) was required, increasing the HHV of the oil produced at $350{ }^{\circ} \mathrm{C}$ by $36 \%$. The relationship between temperature and energy flows for the process is shown in Fig. 2.

The lower energy output (HHV of oil), compared to the high energy input presents several opportunities to improve heat recovery and reactor design. Eliminating energy losses in the process may diminish the energy wastes and this posits the feasibility of the liquefaction process at the large scale.

Different biomass/solvent ratios resulted in differences in both oil yield and conversion. An increase of solvent mass in the system

\begin{tabular}{|c|c|c|c|c|c|c|c|}
\hline \multirow{2}{*}{$\begin{array}{l}\text { Conversion products } \\
\text { (wt } \%)\end{array}$} & \multicolumn{3}{|c|}{$\begin{array}{l}\text { Temperature } \\
\left({ }^{\circ} \mathrm{C}\right)\end{array}$} & \multicolumn{4}{|c|}{ Biomass/solvent ratio } \\
\hline & 250 & 300 & 350 & $1: 10$ & $1: 15$ & $1: 20$ & $1: 25$ \\
\hline Oil & 39.0 & 44.5 & 47.3 & 33.5 & 44.5 & 49.0 & 50.5 \\
\hline SR & 51.0 & 43.0 & 37.8 & 50.8 & 43.0 & 39.3 & 34.5 \\
\hline RP & 10.0 & 12.5 & 15.0 & 15.7 & 12.5 & 11.7 & 15.0 \\
\hline
\end{tabular}
improved fragmentation of biomass by reaching supercritical conditions and enhanced dissolution of depolymerised biomass

Table 2 Product yields distribution for A. donax 


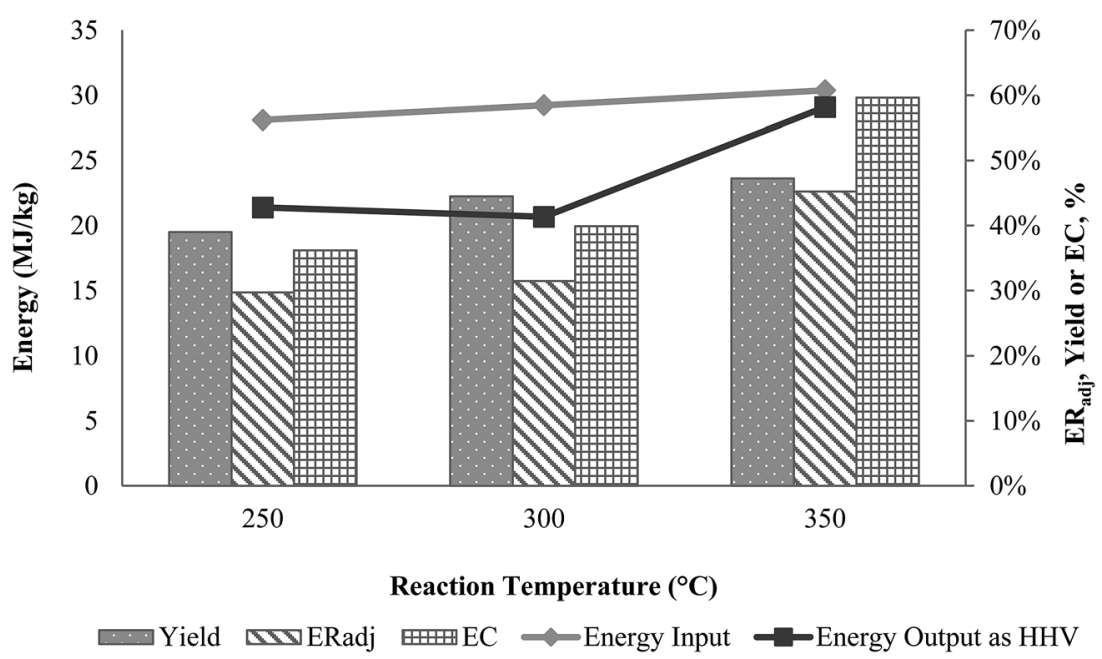

Fig. 2 Effect of reaction temperature on oil yield, conversion and energy output (HHV) in liquefaction of $A$. donax. Energy input is a function of reaction temperature.

components. ${ }^{30}$ This effect was confirmed by oil yield increasing from $33.5 \mathrm{wt} \%$ to $50.5 \mathrm{wt} \%$ in $\mathrm{B} / \mathrm{S}$ ratio range $1: 10$ to $1: 25 \mathrm{wt} / \mathrm{wt}$. Raising solvent ratio from $1: 10$ to $1: 25 \mathrm{w} / \mathrm{wt}$ saw an increase HHV of oil by $20 \%$ and of energy conversion by $80 \%$. Fig. 3 shows the oil yield and conversion increased with increasing amount of solvent. The increases were significant as the yield and HHV increased from $1: 10$ to $1: 15$ and $1: 20$, but less so from $1: 20$ to $1: 25$. Conversely, higher feedstock mass to solvent ratio had the tendency to behave like pyrolysis which leads to SR increase. ${ }^{7} \mathrm{~A}$ decrease in amount of solvent in the slurry from $1: 25$ to $1: 10$ led to the increase of SR by $16 \mathrm{wt} \%$. B/S ratio plays an important role in commercial continuous reactors in achieving ideal flow rate of slurry at pumping section, for this purpose, $1: 15$ ratio was used for the various feedstocks experiments.

\subsection{Effect of recycling solvent on the process}

In these experiments, acetone recovered from products was recycled into the liquefaction process. The first and second recycles comprise $43 \mathrm{wt} \%$ of total solvent; while the third recycle used $100 \mathrm{wt} \%$ recycled acetone. The percentage represents how much of recycled solvent was mixed with the fresh solvent to achieve the target biomass to solvent ratio. Some solvent was lost upon recovery due to the nature of separation of the solvent (rotary evaporator) from the oil. The percentage was determined based on the average percentage of recovered solvent from the experiments. Furthermore we have run one experiment with $100 \%$ of recycled solvent that would be more relevant for large scale production.

It should be noted that only the solvent mass was recycled in these experiments, and energy was not recovered from products since the solvents are cooled to room temperature prior to mixing with biomass. However, a theoretical energy recovery was calculated to simulate the energy savings of recycling the heat from the hot solvent back into the liquefaction process. The product yields distributions from all recycled cycles are shown in the ESI data (Table S1†).

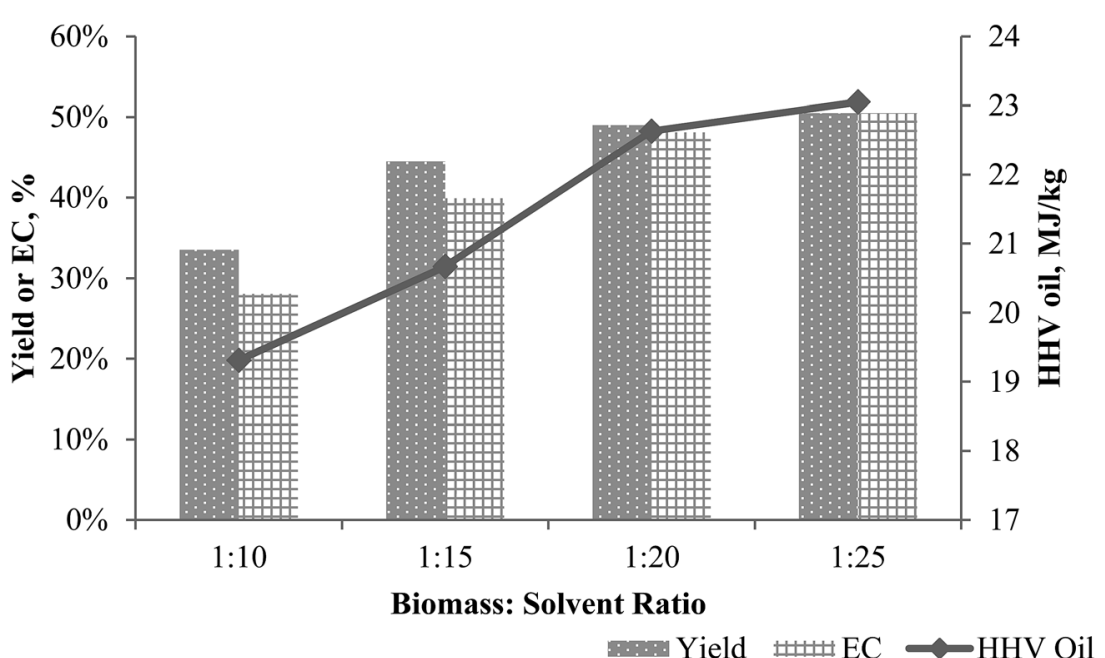

Fig. 3 Yield, conversion and HHV oil trend of varying solvent amounts from A. donax. 
The trend of HHV of oil produced in these experiments was similar to the trend of the oil yield for the recycled acetone runs (Fig. 4). The zeroth run (pure acetone) can be used as the baseline. HHV of the oils in the recycle runs varied slightly, with higher HHVs of oils produced using recycled solvents. Higher HHV for the first and second recycle runs may have been caused by increased organic conversion. While the amount of biomass was the same for all runs, there was more organic content in the recycled run. The volatile organic components that were evaporated with acetone during separation are presented in the ESI data (Table S2 $\dagger$ ). The organic acids and phenolic compounds were prevalent in the recycled solvent. The acid originated from the secondary degradation of sugars hydrolysed from cellulose and hemicellulose. Moreover, organic solvent increased the solubility of lignin and its decomposition products such as phenolic compounds observed in the recycled solvent. These compounds could have been further degraded in subsequent liquefactions into gas phase, or could have affected the reactions within the process. ${ }^{36}$ This behaviour was observed between the first and third runs as a decrease of oil and SR yield by $8 \mathrm{wt} \%$ and $3.9 \mathrm{wt} \%$, respectively, while gas and solvent yield increased sharply. In addition, a rapid increase was observed for SR and oil yields. This could have been due to the declining availability of acetone as a solvent or/and the presence of the acids in recycled solvent. It means that the decomposition temperature of lignin, generally responsible for SR formation, decreased with addition of acids into organic solvents. ${ }^{37}$ The organic components dissolved in acetone, in the progressively increasing concentrations in the recycled solvents might be interfering with the reactions rather than benefiting the process.

In conjunction with higher HHVs, energy recovery also improved in recycle runs due to the energy savings from the elevated temperature of the incoming recycled solvent, decreasing additional energy input. The declining energy recovery in repeated recycles was due to the decreasing $\mathrm{HHV}$ and yield of product oil.

\subsection{Various lignocellulosic feedstock applications}

Table 3 shows the HHV of feedstocks and product oils from runs at $300{ }^{\circ} \mathrm{C}$. The HHVs of the biomasses varied from $16.7 \mathrm{MJ}$ $\mathrm{kg}^{-1}$ in Ba to $19 \mathrm{MJ} \mathrm{kg}^{-1}$ in BBS, which is in line with relevant carbon and oxygen content. Similar HHV of AD, Ba, BBS, PT were reported in the literature. ${ }^{10,23,27,28}$ The results demonstrate improvement in HHV of bio crude oils from feedstocks. These improvements translate into appreciable increases in higher heating value. The significant increase of HHV can be observed for all feedstocks except Arundo donax, where slight change occurred. However, in Section 3.1, it was observed that Arundo donax liquefied at $350{ }^{\circ} \mathrm{C}$ had significantly higher $\mathrm{HHV}$ compared with the oil produced at $300{ }^{\circ} \mathrm{C}$. Energy recovery is also higher at $350{ }^{\circ} \mathrm{C}$. This confirms results from previous studies that different energy inputs are required to achieve optimum product oil quality from liquefaction of different feedstock. ${ }^{7}$ A recent study by Jablonský et al. ${ }^{33}$ showed that HHV can be predicted based on the carbon content. The comparison between the calculated and measured values revealed 0.75$5.4 \%$ difference (i.e. absolute error). Nhuchhen and $\mathrm{Afzal}^{38}$ analysed 59 models to predict HHV where the absolute error was in the range of $4.81-37.27 \%$. The absolute errors determined from the models based on elemental composition were up to $10 \%$. Therefore, the model used in this publication is suitable for HHV prediction.

Fig. 5 shows the product yield and HHV of liquefaction of the various biomass species with acetone as a solvent at $300{ }^{\circ} \mathrm{C}$. Oxygenated compound and aromatics in the bio-crude oil are important parameters, especially in combustion chemistry as these can cause harmful organic compounds in diesel engine exhaust. ${ }^{39}$ Hence, considering the bio-crude oil quality and improvement of the process efficiency, $300{ }^{\circ} \mathrm{C}$ was preferable, and therefore used for the rest of the experiments. Our selection is also supported by other studies where authors found the highest bio-crude oil yield at $300{ }^{\circ} \mathrm{C}$ with acetone as a solvent. ${ }^{40}$ The oil yields depended on compositional structure of biomass and were varied between $31.5 \mathrm{wt} \%$ (PT) and $62.4 \mathrm{wt} \%$ (BBS), while the SR followed the opposite trend. The highest BBS conversion is attributed to high holocellulose and low lignin content in the raw feedstock. Moreover, the degradation of extractives that generate mostly low molecular compounds intensify with the low solvent polarity. ${ }^{41}$ The SR yields fluctuated slightly among the biomasses in the range of $27.3 \mathrm{wt} \%$ (BBS) to

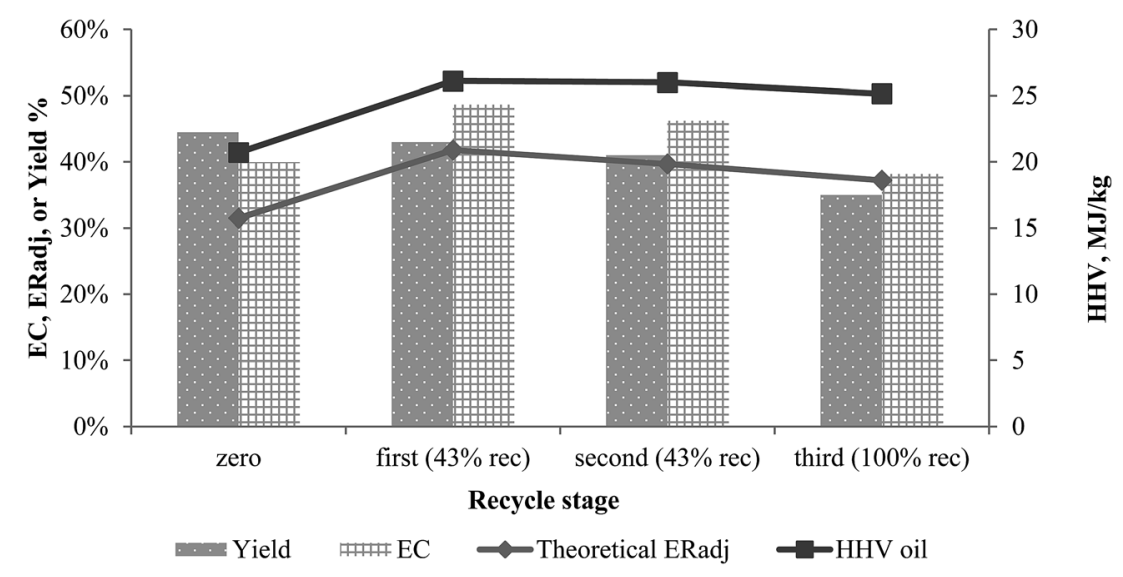

Fig. 4 Effect of solvent recirculation on produced oil yield, HHV and conversion rate. The calculated theoretical energy recovery is also shown. 
Table 3 HHV of feedstock and product oils from different feedstock

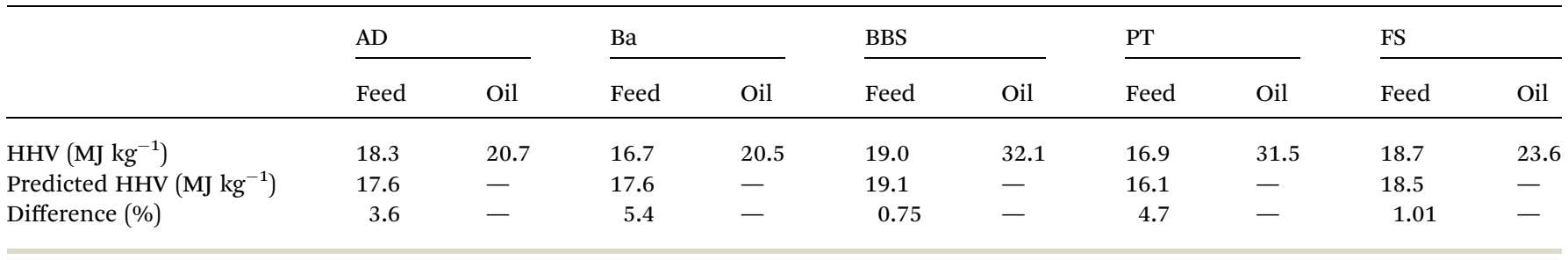

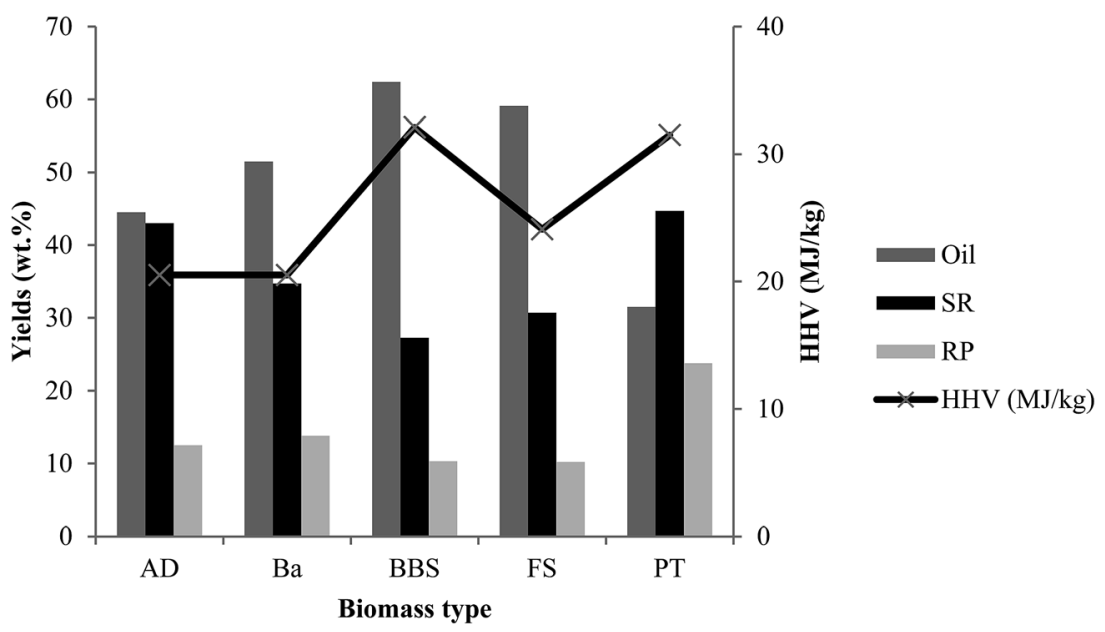

Fig. 5 Product yields dependence on biomass type.

44.7 wt\% (FS). The excessive values of SR are a result of inhibition of secondary reactions, such as hydrolysis caused by high ash content with lignin in the biomasses. ${ }^{37}$ Furthermore, slow heating rate of the reactor $\left(3{ }^{\circ} \mathrm{C} \mathrm{min}^{-1}\right)$ may increase the SR production due to secondary reactions. The different biomass didn't have significant impact on RP yields that were in lower ranges (10-14 wt\%) except PT with the highest amount of these products ( $24 \mathrm{wt} \%$ ) which may be due to insufficient degradation of high extractives and lignin contents in the raw feedstock. Overall, considering the oil yields, the biomass degradation efficiency in liquefaction process can be sequenced: $\mathrm{BBS}>$ FS $>$ $\mathrm{Ba}>\mathrm{AD}>\mathrm{PT}$. A limited number of publications focused on liquefaction of similar biomass. Comparing the results with the relevant literature, Minowa et al. ${ }^{27}$ conducted liquefaction of pineapple leaves using water as solvent and sodium carbonate catalyst at $300{ }^{\circ} \mathrm{C}$. Under these conditions the bio-crude oil yield was $23.6 \%$ which was considerably lower than $31.5 \%$ using acetone as solvent and no catalyst. A number of research groups have processed bagasse through liquefaction using ethanol and/or water as solvent at various temperatures. ${ }^{\mathbf{1 0 , 2 6}}$ The biocrude oil yields increased with the ethanol percentage in the solvent. Overall, it can be seen that organic solvents have remarkable effects on liquefaction. Aysu and Kucuk ${ }^{35}$ used different solvents and determined that among solvents included in the study, the highest oil yields were reached with 2butanol and then acetone. With regard to banana waste, a number of articles indicated its high potential to generate energy by combustion, pyrolysis or ethanol production. ${ }^{18,28}$ This study demonstrated liquefaction as another potential energy conversion process for BBS.

The correlation coefficient was calculated to examine the relationship between structural composition of the raw feedstock and product yields (bio-crude and SR). The correlations were only modest, for instance, between lignin and SR, the Pearson correlation coefficient was +0.727 and the $R$-squared value is 0.529. In contrast with the conclusions of other studies, ${ }^{7,27}$ the correlation of lignin with SR yield cannot be established from the results in this study. The relationship between lignin content of the feed and the product yields may not be discernible because of the variances in the structure and composition of the lignin in diverse biomasses. ${ }^{42}$

The observed trends could be affected by either different ash compositions of the feedstocks interacting during liquefaction or solvent character. Comparing the HHVs of feedstock and oil, it is clear that liquefaction has been successful in producing oil that has greater energy density than biomass. Oil produced from banana has the highest HHV among the feedstocks studied, with $69 \%$ higher HHV than the feedstock. Bio-crude produced from bagasse had the lowest HHV, but still has $23 \%$ better HHV than the original feedstock. We can see that for some feedstock, i.e. $\mathrm{AD}, \mathrm{Ba}$ and $\mathrm{FS}$, there is a large quantity of relatively low HHV oil produced. For PT, it is the opposite, as there is a low amount of oil produced albeit with a high HHV.

Using EC and oil yield, the use of the different feedstocks in liquefaction was assessed. 
Fig. 6 shows how each feedstock performed in liquefaction. The oil yield provides an indicator of the quantity of oil that can be produced from a certain biomass feedstock. EC is the composite indicator for quantity and quality of oil. An exceptional feedstock, as shown in.

Fig. 6, is BBS, which has high yield and HHV. This is further confirmed by an EC of $161 \%$, the only feedstock in the study that adequately concentrated the chemical energy in the oil by undergoing liquefaction, possibly eliminating the oxygen content of the feedstock as it converts to oil. When the energy input is considered, however, the energy recovery of BBS liquefaction is lower. This highlights the larger energy requirement to produce a more energy dense biocrude from a less energy dense feedstock. The observed quality and conversion efficiency for the various feedstocks can be related to the chemical composition of the feedstock which is further discussed in Section 4.

In the analysis of the relationship of the chemical make-up of feedstock and the product oil, it has been observed that the varying lignin content of the different lignocellulosic feedstocks has no linear correlation with the oil HHV or yield (Fig. 7). Although the low lignin BBS produced oil with high HHV, PT with almost three times higher lignin content performed similarly. Other feedstock with lignin contents similar to PT were converted to oil with varying HHV. The effect on oil yield was also observed to be independent of the lignin content.

\section{Chemical characterisation of oil and solid residues}

\subsection{GC-MS analysis of oils}

The liquefaction oils are complex of various chemical compounds that are difficult to separate effectively by FTIR or GC-MS, although information from these analyses provide an insight into potential reactions in liquefaction process. The oils obtained at three different temperatures and from various biomasses were qualitatively characterised by GC-MS. Overall, around 39 components were detected within $57-92 \%$ of total

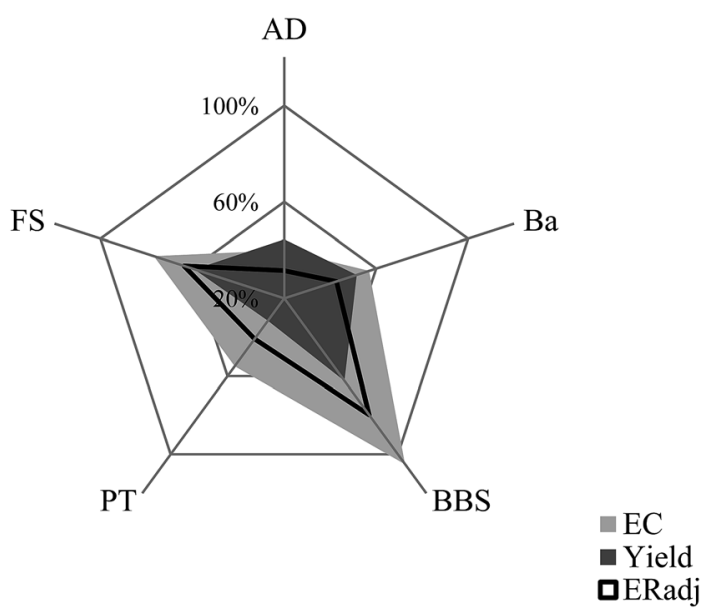

Fig. 6 Yield and conversion of five different lignocellulosic feedstocks.

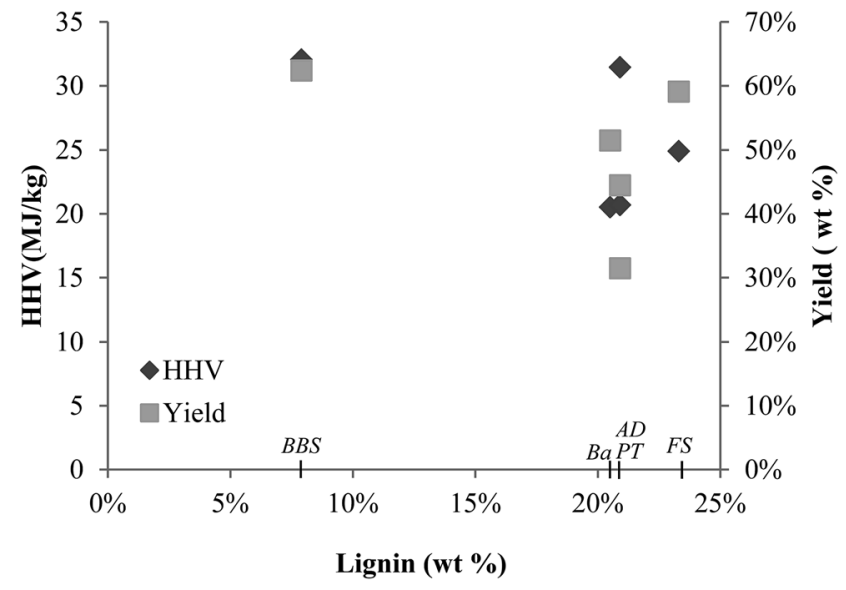

Fig. 7 Effect of feedstock lignin content to biocrude high heating value and yield.

chromatogram area and tentatively identified by comparing their mass spectra with those from the NIST database. The identified compounds from the oils are listed in Tables 4 and S3 (ESI data $\dagger$ ) with proportional percentage of their peak area to total area.

According to GC-MS analysis the identified components were phenolics, carboxylic acids, alcohols, ketones, esters and aromatics compounds, with their abundance greatly affected by temperature. Carboxylic acids, phenolics and ketones were the most present in the oils with ketones rapidly increasing, while acids and phenolics decreased with cumulative temperature. Various types of acids were found in the oils such as short-chain carboxylic acids and short-chain fatty acids. They might be formed from extractives or cellulose and hemicellulose components by complex degradation reactions; ${ }^{\mathbf{4 3}}$ however, they dropped rapidly from $25 \%$ to $1 \%$ of total peak area with increasing temperatures. This downturn could be caused by the breaking down of acids into gaseous products like $\mathrm{CO}_{2}$ and $\mathrm{CH}_{4} \cdot{ }^{44}$ Phenolic compounds, mainly 4-ethyl-2-methoxyphenol, 2,6-dimethoxyphenol and 2-methoxyphenol, were produced by hydrolysis and degradation of lignin that is enhanced with the higher solvent density. An increase of temperature led to a decrease of phenolics in oils presumably by depolymerization of phenolics into gaseous or solids products. ${ }^{36}$ Large amounts of cyclic and aliphatic ketones were observed in the oils at $250{ }^{\circ} \mathrm{C}$, $300{ }^{\circ} \mathrm{C}$ and $350{ }^{\circ} \mathrm{C}$ that accounted for more than $20 \%, 50 \%$ and $70 \%$ of total chromatogram area, respectively. The production paths for ketones are not straightforward but they could be formed from intermediates degraded from lignocellulosic components. ${ }^{44}$ The presence of alcohols was minor and altered from $250{ }^{\circ} \mathrm{C}$ to $300{ }^{\circ} \mathrm{C}$. Only one aldehyde, furfural, was observed at $250{ }^{\circ} \mathrm{C}$ as a product of subsequent degradation of sugars from hemicellulose which is undergoing further degradation at higher temperature. Deoxygenation at high temperatures produced a low amount of alkenes and aromatics.

Table 4 indicates the diverse chemical composition of the oils as related to the various chemical composition of different biomasses. The amount of ketones was greatest through each 
Table 4 Major compounds from oils produce from different biomasses ${ }^{a}$

\begin{tabular}{|c|c|c|c|c|c|c|c|}
\hline \multirow[b]{2}{*}{ No. } & \multirow[b]{2}{*}{$\mathrm{RT}(\min )$} & \multirow[b]{2}{*}{ Chemical compound name } & \multicolumn{5}{|c|}{ Area (\%) } \\
\hline & & & $\mathrm{AD}$ & $\mathrm{Ba}$ & BBS & FS & PT \\
\hline 2 & 3.01 & 4-Methyl-2-pentene & 5.32 & 4.64 & 1.36 & 3.24 & - \\
\hline 3 & 3.06 & 4-Methyl-3-penten-2-one & 7.97 & - & 25.03 & 12.08 & 45.2 \\
\hline 4 & 3.4 & (Z)-4-Methyl-2-pentene & - & 4.69 & 2.89 & & 1.86 \\
\hline 7 & 4.64 & 4-Hydroxybutanoic acid & 1.23 & - & - & - & - \\
\hline 8 & 4.72 & 2,3,4,5-Tetramethyl-2-cyclopenten-1-one & - & 1.05 & - & - & - \\
\hline 9 & 4.85 & 2,5-Hexanedione & 6.7 & 8.94 & - & 4.93 & 2.59 \\
\hline 10 & 5.02 & $\mathrm{D}-(+)-1,2$-Isopropylideneglycerol & - & - & - & 4.91 & - \\
\hline 11 & 5.18 & 2-(1-Hydroxy-1-methyl-2-oxopropyl)-2,5-dimethylfuran-3(2H)-one & 2.17 & 3.12 & - & 1.22 & 1.21 \\
\hline 12 & 5.46 & 3-Methyl-2-cyclopenten-1-one & - & 5.3 & - & 1.09 & - \\
\hline 17 & 6.63 & 4-Hydroxy-2-methylbutanoic acid & 6.84 & 7.74 & - & 3.18 & 5.97 \\
\hline 18 & 6.66 & 2,3-Dimethyl-2-cyclopenten-1-one & - & - & 4.39 & - & 3.92 \\
\hline 19 & 6.95 & 3-Methyl-2-cyclohexen-1-one & - & - & 1.78 & - & - \\
\hline 20 & 7.19 & $(3 Z, 5 E)-2,7$-Dimethyl-3,5-octadiene & 4.75 & - & 4.35 & - & 2.18 \\
\hline 21 & 7.48 & 2-Methoxyphenol & 5.38 & 2.48 & 1.02 & 1.03 & 2.45 \\
\hline 22 & 7.66 & 3,3-Dimethyl-4,5-heptadien-2-one & - & - & 2.51 & - & - \\
\hline 23 & 7.71 & 3,5-Dimethyl-2-cyclohexen-1-one & - & - & 4.95 & - & 1.6 \\
\hline 24 & 7.81 & 2,6-Dimethyl-2,5-heptadien-4-one & 2.17 & 1.42 & 6.14 & - & 3.01 \\
\hline 25 & 8.01 & 3,5,5-Trimethyl-2-cyclohexene-1-one & - & - & 18.88 & - & - \\
\hline 26 & 8.66 & 4-Ethylphenol & 8.2 & 20.1 & - & 2.32 & 4.17 \\
\hline 27 & 8.69 & 2,3-Dimethylphenol & - & - & 1.04 & - & - \\
\hline 28 & 8.98 & 2-Acetonylcyclopentanone & 2.73 & - & - & 1.37 & 1.13 \\
\hline 29 & 9.02 & 4-(2-Furyl)-3-buten-2-one & 1.52 & 1.74 & - & - & - \\
\hline 38 & 13.25 & 2,3-Dihydro-5,7-dimethyl-1 $H$-inden-1-one & - & - & 1.23 & - & - \\
\hline 39 & 13.9 & 5-tert-Butylpyrogallol & 1.1 & - & - & - & - \\
\hline Total & & & 86.82 & 89.24 & 94.89 & 50.75 & 91.62 \\
\hline
\end{tabular}

sample except $\mathrm{Ba}$ where phenolics were predominant. The reason is that $\mathrm{Ba}$ contained the lowest percentage of holocellulose among the feedstocks in contrast with BBS were prevalent percentage of holocellulose had beneficial effect on the formation of the highest amount of ketones. Three short acids were analysed in only two oils, with the highest peak in AD samples as a consequence of high amounts of sugars. From the alkene group, 4-methyl-2-pentene and ( $Z$ )-4-methyl-2-pentene were present in Ba and BBS. Alcohols, aromatics were detected in minor amounts in most samples.

\subsection{FTIR analysis of SR}

The various lignocellulosic compositions among the feedstocks had strong influence on the chemical composition of the product oils, which is also closely connected with physical properties. ${ }^{45}$ Many studies have found that cellulose, hemicellulose and lignin fractions, which are the major components of biomass, behave differently under thermal liquefaction conditions. $^{36}$

FTIR spectrums of raw AD feedstock and SR after liquefaction for three different temperatures are compared in Fig. S1 (ESI data $\dagger$ ). The observed functional groups with their wavenumber were assigned according to the related references. ${ }^{23,46-48}$ Two sharper peaks appeared in the range 2850-2990 $\mathrm{cm}^{-1}$ representing the $\mathrm{C}-\mathrm{H}$ stretching of $\mathrm{CH}_{3}, \mathrm{CH}_{2}$ - groups in cellulose and hemicellulose components. ${ }^{23}$ However, the intensity of these groups in SR was decreasing with the temperature increase due to their decomposition into oil phase. The broad peak between 3200 and $3500 \mathrm{~cm}^{-1}$ corresponded to 
a combination of aliphatic and aromatic $\mathrm{O}-\mathrm{H}, \mathrm{C}-\mathrm{H}$ and $\mathrm{N}-\mathrm{H}$ stretching groups. ${ }^{9}$ The most informative absorption part of spectrum was at $800-1800 \mathrm{~cm}^{-1}$ which belongs to many different groups. Carbonyl groups $(\mathrm{C}=\mathrm{O}$ stretching) are typically observed from 1650 to $1750 \mathrm{~cm}^{-1}$ and their presence was increasing in SR in comparison with raw feedstock due to degradation of hemicellulose into sugars. ${ }^{36}$ This might indicate that the reaction between $\mathrm{AD}$ and acetone created insoluble polymers containing $\mathrm{C}=\mathrm{O}$ groups. The presence of lignin observed around $1500 \mathrm{~cm}^{-1}$ and $1600 \mathrm{~cm}^{-1}$ provided the evidence of the lignin fragments at all temperatures in SR. The broad intensity in the range of 950 to $1200 \mathrm{~cm}^{-1}$ was occurring as a result of the $\mathrm{C}-\mathrm{O}$ bonds in carbohydrates which are presented by any sugars in the samples. In the higher temperatures at 300 and $350^{\circ} \mathrm{C}$ new vibrations appeared between 690 and 800 $\mathrm{cm}^{-1}$ that might be related with the possible occurrence of single, polycyclic, and substituted aromatic groups. ${ }^{\mathbf{4 4 , 4 6}}$

Fig. S2 (ESI data†) illustrates FTIR spectra of various raw materials and their SR derived from the same process conditions $\left(300{ }^{\circ} \mathrm{C}, 30 \mathrm{~min}\right.$ in $\mathrm{N}_{2}$ atmosphere). The results are showing that $\mathrm{O}-\mathrm{H}$ and $\mathrm{C}-\mathrm{H}$ stretching groups decreased in all samples whereas almost diminished in FS and Ba. In most of the spectrums of SR (except FS) the presence of absorption peaks around 1050 and $1160 \mathrm{~cm}^{-1}$ confirmed that cellulose was not liquefied completely. The absorbance of lignin (1230-1600 $\mathrm{cm}^{-1}$ ) was mostly present in each sample; however, the lower intensity of the vibrations in SR indicated partial degradation. All samples obtained C-O stretch vibrations occurring between 1000-1100 $\mathrm{cm}^{-1}$ due to presence of primary and secondary carbohydrates.

\section{Conclusion}

Overall, liquefaction is demonstrated for a diverse range of biomass. Liquefaction of $A$. donax was investigated using different temperatures (250-350 $\left.{ }^{\circ} \mathrm{C}\right)$, solvent recycling regimes and biomass/solvent ratio $(1: 10$ to $1: 25)$ for improving the quality and quantity of oil. The oil yield was maximized at $350{ }^{\circ} \mathrm{C}$ and $1: 25 \mathrm{~B} / \mathrm{S}$ ratio. For liquefaction of different feedstock (BBS, Ba, FS and PT), $300{ }^{\circ} \mathrm{C}$ and $1: 15$ were employed. BBS had the highest oil yield ( $62 \mathrm{wt} \%$ ), followed by other feedstocks in the order: $\mathrm{FS}>\mathrm{Ba}>$ $\mathrm{AD}>\mathrm{PT}$. The first recycle of solvent (43\% of total solvent) improved HHV by $26 \%$ with the positive effect on energy recovery. The varying lignin content across the feedstock used was determined to not be correlated with the HHV of oils produced. The GCMS results showed the change in distribution and relative abundance of the compounds (mainly oxygenated) depending on temperature and type of biomass. Interestingly, the HHVs didn't show any strong correlation with the structural components of the raw feedstock. Analysis of energy input and output of varying conditions and feedstock showed energy requirements and effects to HHV of produced oils and yield. This demonstrated the potential for large-scale production via liquefaction.

\section{Acknowledgements}

The authors appreciatively acknowledge the financial support provided by QUT, a PhD scholarship from the School of
Chemistry, Physics and Mechanical Engineering and an ECARD grant. We express gratitude to the QUT Central Analytical Research Facility (CARF) for their assistance.

\section{References}

1 I. Chapman, Energy Policy, 2014, 64, 93-101.

2 A. Eisentraut, Sustainable production of second-generation biofuels, International Energy Agency, France, 2010.

3 A. Azad, M. Rasul, M. Khan, S. C. Sharma and M. Hazrat, Renewable Sustainable Energy Rev., 2015, 43, 331-351.

4 J. Kosinkova, A. Doshi, J. Maire, Z. Ristovski, R. Brown and T. J. Rainey, Renewable Sustainable Energy Rev., 2015, 49, 1271-1285.

5 A. Eisentraut, Sustainable production of second-generation biofuels, International energy agency, France, 2010.

6 S. S. Toor, L. Rosendahl and A. Rudolf, Energy, 2011, 36, 2328-2342.

7 J. Akhtar and N. A. S. Amin, Renewable Sustainable Energy Rev., 2011, 15, 1615-1624.

8 G. Van Rossum, W. Zhao, M. Castellvi Barnes, J. P. Lange and S. R. Kersten, ChemSusChem, 2014, 7, 253-259.

9 Z. Liu and F.-S. Zhang, Energy Convers. Manage., 2008, 49, 3498-3504.

10 J. Kosinkova, J. A. Ramirez, J. Nguyen, Z. Ristovski, R. Brown, C. S. K. Lin and T. J. Rainey, Biofuels, Bioprod. Biorefin., 2015, 9, 630-638.

11 F. Behrendt, Y. Neubauer, M. Oevermann, B. Wilmes and N. Zobel, Chem. Eng. Technol., 2008, 31, 667-677.

12 X. Yuan, H. Li, G. Zeng, J. Tong and W. Xie, Energy, 2007, 32, 2081-2088.

13 L. Corno, R. Pilu and F. Adani, Biotechnol. Adv., 2014, 32, 1535-1549.

14 C. Williams and T. Biswas, Commercial Potential of Giant Reed for Pulp, Paper and Biofuel Production, Rural Industries Research and Development Corporation, Australia, 2010.

15 T. J. Rainey, W. O. Doherty and S. Sharman, Appita J., 2014, 67, 128.

16 A. P. Griffith, M. Haque and F. M. Epplin, Appl. Energy, 2014, 127, 44-54.

17 Australian Banana Grower's Council, Banana industry: Key facts, http://abgc.org.au/banana-industry-2/our-industry/ key-facts/, accessed 29 of June, 2015.

18 E. R. K. Fernandes, C. Marangoni, O. Souza and N. Sellin, Energy Convers. Manage., 2013, 75, 603-608.

19 Department of Agriculture Fisheries and Forestry, Australian Pineapple Industry: Strategic Plan 2011-2016, 2011, vol. 1, pp. 5-6.

20 P. Saravanan, R. Muthuvelayudham and T. Viruthagiri, J. Eng., 2012, 2013, 979547.

21 T. J. Rainey, PhD thesis, Queensland University of Technology, 2009.

22 M. Puri, R. E. Abraham and C. J. Barrow, Renewable Sustainable Energy Rev., 2012, 16, 6022-6031.

23 R. Saikia, R. S. Chutia, R. Kataki and K. K. Pant, Bioresour. Technol., 2015, 188, 265-272. 
24 R. Yin, R. Liu, Y. Mei, W. Fei and X. Sun, Fuel, 2013, 112, 96104.

25 T. Aysu and H. Durak, Biofuels, Bioprod. Biorefin., 2015, 9, 231-257.

26 J. Chumpoo and P. Prasassarakich, Energy Fuels, 2010, 24, 2071-2077.

27 T. Minowa, T. Kondo and S. T. Sudirjo, Biomass and Bioenergy, 1998, 14, 517-524.

28 N. Abdullah, F. Sulaiman, M. A. Miskam and R. M. Taib, International Journal of Biological, Veterinary, Agricultural and Food Engineering, 2014, 8, 712-716.

29 J. L. Guimarães, E. Frollini, C. G. da Silva, F. Wypych and K. G. Satyanarayana, Ind. Crops Prod., 2009, 30, 407-415.

30 H. J. Huang and X. Z. Yuan, Prog. Energy Combust. Sci., 2015, 49, 59-80.

31 A. Demirbaş, Energy Convers. Manage., 2000, 41, 1601-1607. 32 A. Demirbaș, Energy Convers. Manage., 2000, 41, 633-646.

33 M. H. Jablonský, A. Ház, A. Orságová, M. Botková, L. Šmatko and J. Kočiš, Relationships between elemental carbon contents and heating values of lignins, in 4th International Conference Renewable Energy Sources, Bratislava, Slovakia, 2013.

34 C. Dupont, R. Chiriac, G. Gauthier and F. Toche, Fuel, 2014, 115, 644-651.

35 T. Aysu and M. M. Küçük, Fuel, 2013, 103, 758-763.
36 A. A. Peterson, F. Vogel, R. P. Lachance, M. Fröling, M. J. Antal Jr and J. W. Tester, Energy Environ. Sci., 2008, 1, 32-65.

37 S. Kang, X. Li, J. Fan and J. Chang, Renewable Sustainable Energy Rev., 2013, 27, 546-558.

38 D. R. Nhuchhen and M. T. Afzal, Bioengineering, 2017, 4, 7.

39 F. Hedayat, S. Stevanovic, A. Milic, B. Miljevic, M. N. Nabi, A. Zare, S. E. Bottle, R. J. Brown and Z. D. Ristovski, Sci. Total Environ., 2016, 545-546, 381-388.

40 P. Saravanan, R. Muthuvelayudham and T. Viruthagiri, J. Eng., 2013, 2013, 8.

41 H. Rabemanolontsoa and S. Saka, RSC Adv., 2013, 3, 39463956.

42 T. Güngören Madenoğlu, N. Boukis, M. Sağlam and M. Yüksel, Int. J. Hydrogen Energy, 2011, 36, 14408-14415.

43 C. Xu and N. Lad, Energy Fuels, 2007, 22, 635-642.

44 Z. Zhu, L. Rosendahl, S. S. Toor, D. Yu and G. Chen, Appl. Energy, 2015, 137, 183-192.

45 J. A. Ramirez, R. J. Brown and T. J. Rainey, Energies, 2015, 8, 6765-6794.

46 Y. Qian, C. Zuo, J. Tan and J. He, Energy, 2007, 32, 196-202.

47 H. Yang, R. Yan, H. Chen, D. H. Lee and C. Zheng, Fuel, 2007, 86, 1781-1788.

48 N. Q. Bui, P. Fongarland, F. Rataboul, C. Dartiguelongue, N. Charon, C. Vallée and N. Essayem, Fuel Process. Technol., 2015, 134, 378-386. 